\title{
How to Turn a Recession into a Depression: The Role of the Media, of the Politicians, and of the Political Analysts
}

\author{
Dimitris Hatzinikolaou \\ University of Ioannina, Department of Economics, Ioannina, Greece \\ E-mail:dhatzini@cc.uoi.gr \\ Received August 4, 2010; revised September 10, 2010; accepted September 15, 2010
}

\begin{abstract}
By modifying slightly a standard neoclassical-synthesis macroeconomic model, this paper investigates the effects of an adverse supply or demand shock on output, employment, investment, prices, interest rates, and the exchange rate. The paper focuses on the possibility of the magnification of these effects by the media, the politicians, and the political analysts, who induce herd behavior by overstating the size of the shock. I find that such behavior destabilizes the economy by magnifying the amplitude of the business cycle and by hurting private investment, which might cause expansions to be shorter and contractions to last longer.
\end{abstract}

Keywords: Media, Newsmakers, Spin, Business Cycle, Herd Behavior, Neoclassical Synthesis

\section{Introduction}

It has long been recognized that the media (television, newspapers, etc.) do not always report plain facts. In their effort to tell a simple and memorable story that is consistent with a prevailing view, they often end up exaggerating. Reference [1] dubbed this type of media bias "spin" and [2] notes that sentiments about current and future economic conditions can be magnified by spin.

In addition to the media, other institutions may also cause spin. For example, the incumbent political party, whose policies have failed and the economy's deficits have reached unsustainable levels, might blame it on the "economic crisis" imported from abroad, because of a small negative shock that has occurred in the global economy, although that shock could not have caused more than a mild recession. Political analysts invited by the media to comment on the "economic crisis" may also focus on explaining what happened and why it can get worse, rather than risking their reputation by expressing a different view based on their own signals [3]. Such "herd behavior" can magnify the effects of the shock and can cause economic agents to adjust their expectations of economic activity downwards and to reduce their spending much more than they should, thus fulfilling these expectations. This is a likely outcome assuming "bounded rationality" on the part of economic agents, who would be faced with high "deliberation costs" if they were to assess the true economic conditions in a fully rational manner [4].

In this paper, I modify slightly a standard neoclassicalsynthesis macroeconomic model in order to investigate the effects of an adverse supply or demand shock on output, employment, investment, prices, interest rates, and the exchange rate. The paper focuses on how these effects can be magnified by the newsmakers and the experts, who often induce herd behavior by overstating the size of the shock. I find that such behavior destabilizes the economy in that it adversely affects the amplitude of the business cycle and possibly its duration. To my knowledge, this has not been done in the literature.

\section{The Basic Model}

I begin by adopting a standard $I S-L M-B P$ model accompanied by the supply side of the economy. In what follows, lower-case letters denote desired quantities (in real terms). Let $x_{g}, x_{m}, x_{f x}$ denote excess demands for goods and services, money, and foreign exchange, respectively.

The equation that describes the $I S$ curve is $x_{g}=c+i+$ $g+(e x-i m)-y=0$, where $c=$ private consumption, $i=$ private investment, $g=$ government purchases, $e x=e x-$ ports, im $=$ imports, and $y=$ output. By defining $c=y-t$ $s$, where $t=$ taxes and $s=$ saving, one can write the $I S$ equation as $x_{g}=i-s+(g-t)+(e x-i m)=0$. The government deficit, $g-t$, is assumed to be exogenous, whereas the other variables that appear in this equation 
are assumed to be determined as follows.

First, investment depends positively on output and negatively on the ex-ante real interest rate, $r-\pi^{e}$, where $r$ $=$ nominal interest rate and $\pi^{e}=$ expected inflation rate, i.e., $\pi^{e}=\left(P^{e}-P_{-1}\right) / P_{-1}$, where $P=$ price level, and $P^{e}=$ expected price level. That is, $i=i\left(r-\pi^{e}, y\right)$, with partial derivatives $i_{1}<0$ and $i_{2}>0$.

Second, the saving function is $s=s(y-t)$, where $s^{\prime}>0$. Third, the export function is ex $=\operatorname{ex}\left(E \times P^{*} / P\right)$, where $e x^{\prime}$ $>0, E \times P^{*} / P=$ real exchange rate, $E=$ nominal exchange rate (the price of foreign currency in terms of the domestic currency), and $P^{*}=$ foreign price level. Fourth, the import function is $i m=i m\left(E \times P^{*} / P, y-t\right)$, where $i m_{1}<0$ and $i m_{2}>0$. Thus, the $I S$ equation can be written as

$$
\begin{aligned}
I S: x_{g} & =i\left(r-\pi^{e}, y\right)-s(y-t)+(g-t) \\
& +\operatorname{ex}\left(E \times P^{*} / P\right)-i m\left(E \times P^{*} / P, y-t\right)=0 .
\end{aligned}
$$

Now consider the $L M$ equation. Assume a flexible exchange-rate regime, so that the balance of payments does not affect the money supply $(M)$. Assume also that the money demand function is $m^{d}=m^{d}(y, r)$, where $m_{1}{ }^{d}>$ 0 and $m_{2}{ }^{d}<0$. Thus, the $L M$ equation can be written as

$$
L M: x_{m}=m^{d}(y, r)-M / P=0 .
$$

Next, consider the $B P$ equation. Since a flexible exchange-rate regime is assumed here, this equation can be written as

$$
\begin{aligned}
B P: x_{f x} & =i m\left(E \times P^{*} / P, y-t\right)-\operatorname{ex}\left(E \times P^{*} / P\right) \\
& -k\left(r-r^{*}-\hat{E}^{e}\right)=0,
\end{aligned}
$$

where $k\left(r-r^{*}-\hat{E}^{e}\right)$ is net capital inflow, assumed to be a positive function of the open interest differential, $r-$ $r^{*}-\hat{E}^{e}$, i.e., $k^{\prime}>0, r^{*}=$ foreign interest rate, and $\hat{E}^{e}=$ expected percentage change in $E$. This completes the demand side of the economy.

On the supply side, assume a standard short-run production function:

$$
y=F(N, \bar{K}), F_{N}>0, F_{K}>0, F_{N N}<0, F_{K K}<0,
$$

where $N=$ employment and $\bar{K}=$ capital stock (assumed to be constant in the short-run). Letting $W$ denote the nominal wage, the labor demand function is

$$
W / P=F_{N}(N, \bar{K}),
$$

whereas the labor supply function is

$$
W / P^{e}=g(N), g^{\prime}>0 .
$$

Solving the last two equations for $W$; imposing equilibrium in the labor market $\left(N^{s}=N^{d}=N^{E}\right)$; and assuming (for simplicity) static expectations, ${ }^{1}$ i.e., $P^{e}=P_{-1}$, yields

$$
P \times F_{N}(N, \bar{K})=P_{-1} \times g(N) .
$$

\section{The Model with a Supply Shock}

Considering (7) as an implicit function of $N$, one can solve for equilibrium employment $\left(N^{E}\right)$ and write:

$$
N^{E}=N\left(P, P_{-1}, \bar{K}\right), N_{P}>0, N_{P-1}<0, N_{K}>0 .
$$

The assumptions $N_{P}>0$ and $N_{K}>0$ are standard, whereas the assumption $N_{P-1}<0$ is made because a higher price level in the previous period means a higher expected price level for the current period (since $P^{e}=$ $\left.P_{-1}\right)$, thus inducing higher wage demands and reducing this period's labor supply, while leaving labor demand unchanged.

Actual employment $(N)$ may differ from equilibrium employment $\left(N^{E}\right)$, however, because of a shock, $\varepsilon$, which has two effects on $N$ : the effect of the shock itself and a herd-behavior effect, $\sigma \varepsilon$, which might occur in the aftermath of the shock. The role of the parameter $\sigma$, where $\sigma \geq$ 0 , is to allow for a magnification of the herd-behavior effect, and its size depends on the intensity with which the shock is propagated by the media. That is, assume

$$
N=N^{E}+(1+\sigma) \varepsilon, \sigma \geq 0 .
$$

The novelty of this paper is the presence of the term (1 $+\sigma) \varepsilon$ on the right-hand side of (9). This term differentiates the present model from a standard neoclassicalsynthesis one. Equation (9) says that actual employment is determined not only by the fundamentals of the labor market, which determine equilibrium employment $\left(N^{E}\right)$, but also by a shock to the labor market $(\varepsilon)$, e.g., a technological shock, an institutional shock, and the like. Because the precise measurement of the shock is costly, however, economic agents do not use their own estimate of the size of the shock, but rely on experts' opinion, namely the media, the politicians, and the political analysts, who often magnify the size of the shock-the herd-behavior effect discussed earlier, implying that the parameter $\sigma$ may be a large positive number.

To understand the twofold effect of the shock de-

${ }^{1}$ This expectations scheme is a special case of the adaptive-expectations model, which is consistent with the assumption of "bounded rationality" introduced in Section 1 [4,5]. As [6] points out, "bounded rationality leads agents to replace optimizing behavioral rules with relatively inflexible rules of thumb," because "agents have limited decision-making capabilities." 
scribed above, consider the following example. ${ }^{2}$ Suppose there is a large negative shock to the labor market (a large negative value of $\varepsilon$ ), say because of a new tax on corporations, which raises their costs and leads them to reduce their level of employment. Even if the value of $\sigma$ is zero, in which case the herd-behavior effect is zero, corporations will reduce their level of employment. If $\sigma$ is a large positive number, however, which implies a large herd-behavior effect, then all firms in the economy (including small businesses) may expect an economywide fall in income, and hence a fall in the demand for their products, so employment may be reduced still further.

Substituting (8) into (9) yields the following employment equation:

$$
N=N\left(P, P_{-1}, \bar{K}\right)+(1+\sigma) \varepsilon .
$$

The "work-horse" model used in this section consists of (1-4) and (10). Note that investment is actually a function of $r$ (not of $r-\pi^{e}$ ), since $\pi^{e}=0$, thanks to the static expectations assumption, $P^{e}=P_{-1}$. The endogenous variables of the model are $y, N, P, r$, and $E$. Totally differentiating (1-4) and (10); assuming that the autonomous parts of the functions $i, s, e x, i m, m^{d}, k, F$, and $N$ do not change (e.g., $d \bar{i}=0, d \bar{s}=0$, etc.); and also assuming that

$$
d P_{-1}=d \bar{K}=d t=d g=d P^{*}=d M=d r^{*}=d \hat{E}^{e}=0,
$$

which leaves $d \varepsilon$ as the only exogenous change in the system, yields the system of Equations (12) in matrix form.

The determinant of this system is

$$
\Delta=A\left(e x^{\prime}-i m_{1}\right) \frac{P^{*}}{P}
$$

where

$$
A=F_{N} N_{P}\left[m_{1}^{d}\left(i_{1}-k^{\prime}\right)-m_{2}^{d}\left(i_{2}-s^{\prime}\right)\right]+\left(i_{1}-k^{\prime}\right) \frac{M}{P^{2}} .
$$

The signs of $A$ and $\Delta$ are negative if the following condition holds:

$$
s^{\prime}>i_{2} .
$$

In the standard saving-investment diagram, taught in introductory macroeconomics courses, (15) is often imposed when illustrating the "paradox of thrift," so it can be called the "paradox-of-thrift condition." In those courses, (15) can also be viewed as a prima facie condition for the equilibrium output and the autonomousspending multiplier to be positive numbers. Thus, it is not an unreasonable condition, and is assumed to hold here, implying that $\Delta<0$ and $A<0 .^{3}$

Using Cramer's rule, one can now calculate the differentials $d y, d N, d P, d r$, and $d E$, and then the partial derivatives $\partial y / \partial \varepsilon, \partial N / \partial \varepsilon, \partial P / \partial \varepsilon, \partial r / \partial \varepsilon$, and $\partial E / \partial \varepsilon$. One can also calculate the derivative $\partial i / \partial \varepsilon=i_{1}(\partial r / \partial \varepsilon)+$ $i_{2}(\partial y / \partial z)$. The results are as follows:

$$
\begin{gathered}
\frac{\partial y}{\partial \varepsilon}=(1+\sigma) A^{-1} F_{N}\left(i_{1}-k^{\prime}\right) \frac{M}{P^{2}}>0, \\
\frac{\partial N}{\partial \varepsilon}=(1+\sigma) A^{-1}\left(i_{1}-k^{\prime}\right) \frac{M}{P^{2}}>0, \\
\frac{\partial P}{\partial \varepsilon}=(1+\sigma) A^{-1} F_{N}\left[m_{2}^{d}\left(i_{2}-s^{\prime}\right)-m_{1}^{d}\left(i_{1}-k^{\prime}\right)\right]<0, \\
\frac{\partial r}{\partial \varepsilon}=-(1+\sigma) A^{-1} F_{N}\left(i_{2}-s^{\prime}\right) \frac{M}{P^{2}}<0, \\
\frac{\partial E}{\partial \varepsilon}=(1+\sigma) \Delta^{-1} F_{N}\left\{\left(i_{2}-s^{\prime}\right)\left[k^{\prime} \frac{M}{P^{2}}+m_{2}^{d}\left(e x^{\prime}-i m_{1}\right) \frac{E P^{*}}{P^{2}}\right]\right. \\
\left.+\left(i_{1}-k^{\prime}\right)\left[i m_{2} \frac{M}{P^{2}}-m_{1}^{d}\left(e x^{\prime}-i m_{1}\right) \frac{E P^{*}}{P^{2}}\right]\right\}=?,
\end{gathered}
$$

$$
\left[\begin{array}{ccccc}
i_{2}-s^{\prime}-i m_{2} & 0 & -\left(e x^{\prime}-i m_{1}\right) \frac{E P^{*}}{P^{2}} & i_{1} & \left(e x^{\prime}-i m_{1}\right) \frac{P^{*}}{P} \\
m_{1}^{d} & 0 & \frac{M}{P^{2}} & m_{2}^{d} & 0 \\
i m_{2} & 0 & \left(e x^{\prime}-i m_{1}\right) \frac{E P^{*}}{P^{2}} & -k^{\prime} & -\left(e x^{\prime}-i m_{1}\right) \frac{P^{*}}{P} \\
1 & -F_{N} & 0 & 0 & 0 \\
0 & 1 & -N_{P} & 0 & 0
\end{array}\right]\left[\begin{array}{c}
d y \\
d N \\
d P \\
d r \\
d E
\end{array}\right]=\left[\begin{array}{c}
0 \\
0 \\
0 \\
0 \\
(1+\sigma) d \varepsilon
\end{array}\right]
$$

${ }^{3}$ Note that in the more restrictive models where income does not enter the investment function, i.e., when $i_{2}=0,(15)$ is automatically satisfied since the marginal propensity to save $\left(s^{\prime}\right)$ is always assumed to be a positive number (between zero and one). 
and

$$
\frac{\partial i}{\partial \varepsilon}=(1+\sigma) A^{-1} F_{N}\left(i_{1} s^{\prime}-i_{2} k^{\prime}\right) \frac{M}{P^{2}}>0 .
$$

Consider a negative shock, i.e., $d \varepsilon<0$. Equations (16-21) predict that output, employment, and investment will fall; the price level and the interest rate will rise; whereas the effect on the exchange rate is ambiguous. This ambiguity is not surprising, however. On the one hand, the increase in the interest rate improves the capital account, thus pushing the currency to appreciate, an effect that is strengthened by the decrease in output, which improves the current account. On the other hand, the increase in the price level implies a real appreciation of the currency, thus worsening the current account and causing the currency to depreciate.

Note that each of the above effects equals the sum of the corresponding effect in the absence of herd behavior (i.e., when $\sigma=0$ ) plus the latter effect times $\sigma$. Thus, $\sigma$ measures the extent of destabilization of the economy induced by herd behavior, which magnifies the amplitude of the business cycle. Herd behavior might also adversely affect the duration of the business cycle, because, according to (21), it hurts private investment, and this is expected to cause expansions to be shorter and contractions to last longer [7].

\section{The Model with a Demand Shock}

The approach of the previous section is now applied to the case of a demand shock. In particular, a negative financial shock is considered. Examples include a series of bank failures, which reduce the money supply; a switch of the public from bonds to money, which increases the demand for money; and the like. In this case, the equation for the $L M$ curve, (2), is modified as follows:

$$
m^{d}(y, r)-[M / P-(1+\varphi) \eta]=0, \varphi \geq 0,
$$

where $\eta$ is the shock and $\varphi$ is a parameter that plays the role of the parameter $\sigma$ in the previous section. Since there is no supply shock in this case, (10) is simply written as

$$
N=N\left(P, P_{-1}, \bar{K}\right) .
$$

The remaining equations of the previous section's model are used here without any change. Thus, the "work-horse" model of this section consists of (1), (22), (3), (4), and (23), where investment is again a function of $r$ (not of $r-\pi^{e}$ ). Again, totally differentiating these equations and solving for the endogenous variables $(d y, d N$, $d P, d r$, and $d E$ ) yields a system which differs from (12) only in that the right-hand-side vector has $-(1+\varphi) d \eta$ as its second element [since (22) is second in the system] and zeros elsewhere. Thus, the expressions for $\Delta$ and $A$ in (13) and (14) remain unchanged. Using Cramer's rule, one can calculate the following partial derivatives:

$$
\begin{gathered}
\frac{\partial y}{\partial \eta}=(1+\varphi) A^{-1} F_{N} N_{P}\left(k^{\prime}-i_{1}\right)<0, \\
\frac{\partial N}{\partial \eta}=(1+\varphi) A^{-1} N_{P}\left(k^{\prime}-i_{1}\right)<0, \\
\frac{\partial P}{\partial \eta}=(1+\varphi) A^{-1}\left(k^{\prime}-i_{1}\right)<0, \\
\frac{\partial r}{\partial \eta}=(1+\varphi) A^{-1} F_{N} N_{P}\left(i_{2}-s^{\prime}\right)>0, \\
\frac{\partial E}{\partial \eta}=(1+\varphi) \Delta^{-1}\left\{F_{N} N_{P}\left[\left(k^{\prime}-i_{1}\right) i m_{2}-\left(i_{2}-s^{\prime}\right) k^{\prime}\right]\right. \\
\left.+\left(k^{\prime}-i_{1}\right)\left(e x^{\prime}-i m_{1}\right) \frac{P^{*}}{P}\right\}<0,
\end{gathered}
$$

and

$$
\frac{\partial i}{\partial \eta}=(1+\varphi) A^{-1} F_{N} N_{P}\left(i_{2} k^{\prime}-i_{1} s^{\prime}\right)<0 .
$$

Since an adverse financial shock is assumed here $(d \eta>$ $0)$, (24-29) predict that output, employment, prices, and investment will fall, whereas the interest rate will rise. As for the effect on the exchange rate, there is no ambiguity in this case. The currency will appreciate on three counts: higher interest rates improve the capital account, whereas lower output and lower prices both improve the current account. Like the parameter $\sigma$ of the previous section, the parameter $\varphi$ measures the extent of destabilization of the economy induced by herd behavior.

\section{Concluding Remarks}

By modifying slightly a version of the neoclassical-synthesis model, this paper investigates the effects of a supply or demand shock on output, employment, investment, prices, interest rates, and the exchange rate. The paper focuses on the role of the parameters that measure the herd behavior effects of the shock, induced by the media, the politicians, and the political analysts, who often overstate the size of the shock. I find that if, in the absence of herd behavior, the effect of the shock on one of these variables is $\alpha$, then, in the presence of such behavior, it is $\alpha$ plus the product of $\alpha$ times the parameter that captures herd behavior. I conclude that herd behavior is destabilizing, since it magnifies the amplitude of the business cycle. It might also adversely affect the duration of the business cycle, since adverse supply or demand shocks are found to hurt investment, and this can cause expansions to be shorter and contractions to last longer. 
Of course, in addition to herd behavior, other causes of shock magnification might also be at work, thus turning into a depression what would otherwise be only a mild recession. Changes in attitudes, uncertainty about upcoming government regulations, and other structural changes that may be in operation simultaneously with the shock, may influence its effect. For example, ${ }^{4}$ the three most recent recoveries in the United States (1991, 2001, and 2009-2010) have been dubbed "jobless recoveries" because output growth was not accompanied by a significant job growth, a phenomenon that can be explained by an expansion in labor productivity. It is possible that during these recessions and the ensuing recovery periods managers altered their rehiring policies and that this extended the recovery periods and had nothing to do with herd behavior. Reference [8] argues that job losses that stem from structural changes (e.g., a permanent fall in demand, technological change, reorganization of production, and the like) are permanent, so the jobs added during a recovery are mostly newly created positions, not rehires. Creating new jobs, however, takes longer than simply recalling laid-off workers, and is riskier because at the beginning of a recovery there is a lot of uncertainty whether the increase in demand will continue. Thus, structural changes can prolong periods of high unemployment, especially when there is no productivity growth.

\section{Acknowledgements}

I wish to thank an anonymous referee of this Journal for his/her useful comments, which improved the paper. The usual disclaimer applies.

\section{References}

[1] S. Mullainathan and A. Shleifer, "Media Bias," NBER Working Paper 9295, Cambridge, MA, 2002.

[2] K. J. Alsem, S. Brakman, L. Hoogduin and G. Kuper, "The Impact of Newspapers on Consumer Confidence: Does Spin Bias Exist?” Applied Economics, Vol. 40, No. 5, 2008, pp. 531-539.

[3] R. J. Shiller, "Conversation, Information, and Herd Behavior," American Economic Review, Vol. 85, No. 2, 1995, pp. 181-185.

[4] J. Conlisk, "Why Bounded Rationality?" Journal of Economic Literature, Vol. 34, No. 1, 1996, pp. 669-700 (a).

[5] G. W. Evans and G. Ramey, "Adaptive Expectations, Underparameterization and the Lucas Critique," Journal of Monetary Economics, Vol. 53, No. 2, 2006, pp. 249-264.

[6] J. Conlisk, "Bounded Rationality and Market Fluctuations," Journal of Economic Behavior and Organization, Vol. 29, No. 2, 1996, pp. 233-250 (b).

[7] V. Castro, "The Duration of Economic Expansions and Recessions: More than Duration Dependence," Journal of Macroeconomics, Vol. 32, No. 1, 2010, pp. 347-365.

[8] E. L. Groshen and S. Potter, "Has Structural Change Contributed to a Jobless Recovery? Federal Reserve Bank of New York," Current Issues in Economics and Finance, Vol. 9, No. 8, 2003, pp. 1-7.

\footnotetext{
${ }^{4}$ In a previous version of the paper, there was no discussion of other possible causes of shock magnification, in addition to herd behavior. I am grateful to an anonymous referee of this Journal for suggesting that I should include such a discussion and for providing me with this example.
} 